\title{
Estimativa da Digestibilidade Aparente de Nutrientes em Dietas para Eqüinos, com o Uso de Óxido Crômico e Indicadores Internos
}

\author{
Chiara Albano de Araújo Oliveira ${ }^{1}$, Fernando Queiroz de Almeida ${ }^{2}$, Sebastião de Campos \\ Valadares Filho ${ }^{3}$, Antônio Assis Vieira², Maria Izabel Vieira de Almeida ${ }^{4}$, Anderson Corassa ${ }^{5}$, \\ Bruna Adese Lopes ${ }^{6}$, Robert Macedo ${ }^{7}$
}

\begin{abstract}
RESUMO - Foram realizados dois ensaios com o objetivo de avaliar a digestibilidade aparente de nutrientes em dietas para eqüinos, utilizando o método da coleta total de fezes e os indicadores óxido crômico, fibra em detergente ácido indigestível (FDAi), fibra em detergente neutro indigestível (FDNi), celulose indigestível (CELi), lignina (LIG) e cinzas insolúveis em detergente ácido (CIDA). No primeiro ensaio, foram utilizados cinco potros mestiços, alimentados com cinco dietas contendo níveis diferenciados de proteína bruta, mantendo a relação concentrado e volumoso em 50:50. O óxido crômico foi utilizado como indicador externo. No segundo ensaio, foram utilizados quatro potros mestiços, alimentados com dietas compostas por feno de coastcross como volumoso e concentrado nas proporções de 40:60, 60:40, 80:20 e 100:00. Nos dois ensaios, os teores de fibra em detergente ácido indigestível, fibra em detergente neutro indigestível, celulose indigestível, lignina e cinzas insolúveis em detergente ácido foram obtidos após incubação in vitro. No primeiro ensaio, a FDAi mostrou-se adequada como indicador interno para estimar a digestibilidade; a CELi, em ambos os ensaios, foi adequada como indicador interno para a estimativa da digestibilidade aparente de nutrientes em dietas para eqüinos. O óxido crômico apresentou baixa recuperação fecal no primeiro ensaio e a LIG, baixa recuperação fecal nos dois ensaios, subestimando os coeficientes de digestibilidade dos nutrientes, sendo inadequada sua utilização para estimativa da digestibilidade. A CIDA, em função da metodologia de coleta fecal, também mostrou-se inadequada para as estimativas de digestibilidade em eqüinos.
\end{abstract}

Palavras-chave: digestibilidade, eqüinos, indicadores, nutrientes

\section{Estimate of Apparent Digestibility of Nutrients in Horses Diets, Using Chromic Oxide and Internal Markers}

\begin{abstract}
Two assays were performed to evaluate the apparent digestibility of nutrients in horses diets, using the total collection of feces method and the markers chromic oxide, indigestible acid detergent fiber (iADF), indigestible neutral detergent fiber (iNDF), indigestible cellulose (iCEL), lignin (LIG), and insoluble acid detergent ashes (ADTA), as markers. In the first assay, five crossbred colts were used, fed five diets with different levels of crude protein, maintaining the relationship 50:50 concentrate to forage. The chromic oxide was used as external marker. In the second assay, four crossbred colts were fed diets composed by coastcross hay as forage and concentrate in the proportions of 40:60, 60:40, 80:20 and 100:00. In both assays, the cotents of indigestible acid detergent fiber, indigestible neutral detergent fiber, indigestible cellulose, lignin and acid detergent insoluble ash were obtained after in vitro incubation. In the first assay, the FDAi showed to be appropriate as internal marker to estimate the digestibility, and in both assays the CELi showed to be appropriate as internal marker for the estimate of apparent digestibility of nutrients of horses diets. The chromic oxide showed low fecal recovery in the first assay and the LIG showed low fecal recovery in both assays, underestimating the apparent digestibility coefficients of nutrients, and was inadequate to estimate the digestibility. ADIA, compared to the total collection of feces method, also showed to be inadequate to estimate the nutrient digestibility in equine.
\end{abstract}

Key Words: digestibility, equines, markers, nutrients

\section{Introdução}

A digestibilidade dos nutrientes nos alimentos é comumente expressa como porcentagem do nutriente que desaparece no balanço entre a ingestão e a excreção (Van Soest, 1994). O sistema de avaliação de alimentos normalmente utilizado para eqüinos tem sido o mesmo usado para ruminantes, embora diferenças importantes no processo de digestão devam ser observadas, por causa da diferença na

\footnotetext{
1 Discente Mestrado em Zootecnia/UFRRJ. E.mail: chiara@zipmail.com

2 Professor Adjunto/UFRRJ - Instituto de Veterinária, BR 465, Km 7, Seropédica, RJ. E.mail: falmeida@ufrrj.br

${ }^{3}$ Professor Titular - DZO - CCA - UFV. E.mail: scvfilho@ufv.br

${ }^{4}$ Professor Adjunto - ZER - CCA - UFES. E.mail: mizabel@cca.ufes.br

${ }^{5}$ Discente de Graduação em Zootecnia - UFRRJ. Bolsista de Iniciação Científica FAPERJ. E.mail: andcorassa@bol.com.br

${ }^{6}$ Discente de Graduação em Zootecnia - UFRRJ. Bolsista de Iniciação Científica PIBIC/CNPq. E.mail: badese@bol.com.br

${ }^{7}$ Discente Doutorado em Agronomia/UFRRJ. E.mail: robertmacedo@yahoo.com.br
} 
compartimentalização do trato digestivo, o que se traduz em diferentes coeficientes de digestibilidade dos nutrientes nos alimentos (Smolders et al., 1990).

A técnica de coleta total de fezes é conhecida como a mais tradicional, exata e confiável técnica para estimar a produção fecal e o coeficiente de digestibilidade dos nutrientes das dietas para eqüinos (Maurício et al., 1996).

A estimativa da digestibilidade dos nutrientes em dietas para eqüinos pode também ser estimada de forma indireta, por meio de indicadores internos e externos (Kotb \& Luckey, 1972). O indicador externo de uso mais freqüente é o óxido crômico e, como método indireto, baseia-se na recuperação total nas fezes do indicador ingerido, alterações na excreção dos indicadores ou na análise dos mesmos nas fezes ou dietas podem comprometer a utilização dos mesmos nos ensaios de digestão. Considerando que os indicadores internos podem ser úteis nos estudos da digestão nos eqüinos, trabalhos iniciais foram desenvolvidos por Alvarenga et al. (1997), avaliando o uso da fibra em detergente neutro indigestível (FDNi), da fibra em detergente ácido indigestível (FDAi), da celulose indigestível e da lignina como indicadores internos em estudos de digestão com dietas com alimentos volumosos. Recentemente, Miraglia et al. (1999) avaliaram o uso dos indicadores internos: cinzas insolúveis em ácido (CIA) e lignina na estimativa da digestibilidade aparente de nutrientes em dietas mistas para eqüinos.

Segundo Maynard et al. (1979), o indicador ideal para determinar a digestibilidade e a produção fecal total deve possuir algumas propriedades fundamentais: indigestibilidade total, ser farmacologicamente inativo no trato digestivo, taxa de passagem no trato digestivo uniforme, poder ser determinado quimicamente e, de preferência, ser uma substância naturalmente presente nos alimentos.

O presente trabalho foi conduzido com o objetivo de avaliar as estimativas dos coeficientes de digestibilidade de nutrientes, em dietas para eqüinos, através do método da coleta total de fezes e com o uso dos indicadores óxido crômico, fibra em detergente ácido indigestível (FDAi), fibra em detergente neutro indigestível (FDNi), celulose indigestível (CELi), lignina (LIG) e cinzas insolúveis em detergente ácido (CIDA).

\section{Materiais e Métodos}

Foram realizados dois ensaios, no primeiro foram utilizados cinco potros mestiços das raças Bretão Postier e Campolina, com peso médio de $330 \mathrm{~kg}$. Os animais receberam cinco dietas com diferentes níveis de proteína bruta, de 7,5; 10,3; 13,3; 16,0 e 18,4\% PB, mantendo a relação concentrado e volumoso em 50:50. $\mathrm{O}$ volumoso consistiu de feno de capim-coastcross moído (Cynodon dactylon) e o concentrado de milho, premix mineral-vitamínico e níveis variáveis de farelo de soja. O óxido crômico foi utilizado como indicador externo, adicionado em nível de $0,5 \%$ da matéria seca do concentrado. A composição e os teores de nutrientes das dietas estão apresentados na Tabela 1.

Os animais foram alimentados ad libitum, sendo as dietas fornecidas três vezes ao dia, às 8,14 e 20 h, e as sobras recolhidas nos cochos diariamente antes do fornecimento da dieta matutina. Durante o período de coleta, as dietas e as sobras foram pesadas individualmente, obtendo-se, assim, o consumo diário de cada animal.

No segundo ensaio foram utilizados quatro potros mestiços, com peso vivo médio de $200 \mathrm{~kg}$, não castrados, com média de idade de 18 meses. Os animais foram alimentados com dietas compostas por feno de capim-coastcross como volumoso e concentrado de modo a fornecer as proporções de volumoso e concentrado de 40:60, 60:40, 80:20 e 100:00, que compuseram os tratamentos 1, 2, 3 e 4 .

A composição das dietas e os percentuais de proteína bruta (PB), fibra em detergente neutro (FDN) e fibra em detergente ácido (FDA) estão apresentados na Tabela 2.

O feno de coastcross foi fornecido picado, duas vezes ao dia, às 7 e $19 \mathrm{~h}$, simultaneamente com o concentrado, em quantidades iguais, exceto no tratamento 4. As dietas foram formuladas considerando-se o consumo diário de $2,0 \%$ do peso vivo dos animais, com base na matéria seca, de acordo com as recomendações do NRC (1989).

Os ensaios foram conduzidos em quatro períodos, sendo cada período experimental dividido em uma fase de adaptação à dieta de sete dias e mais cinco dias para coleta de fezes. As amostras de fezes foram coletadas durante cinco dias, pelo método da coleta total de fezes, diretamente do piso das baias, 
Tabela 1 - Composição percentual dos ingredientes e percentuais de matéria seca (MS), proteína bruta (PB), fibra em detergente neutro (FDN) e cinzas, expressos na matéria seca das dietas (ensaio 1)

Table 1 - Ingredient percentage and contents of dry matter (DM), crude protein (CP), neutral detergent fiber (NDF) and ashes, in dietary dry matter basis (assay 1)

\begin{tabular}{|c|c|c|c|c|c|}
\hline \multirow[t]{2}{*}{ Item } & \multicolumn{5}{|c|}{$\begin{array}{l}\text { Dieta } \\
\text { Diet }\end{array}$} \\
\hline & 1 & 2 & 3 & 4 & 5 \\
\hline $\begin{array}{l}\text { Feno de coastcross } \\
\text { Coastcross hay }\end{array}$ & 50,00 & 50,00 & 50,00 & 50,00 & 50,00 \\
\hline $\begin{array}{l}\text { Milho } \\
\text { Corn }\end{array}$ & 48,17 & 41,46 & 34,75 & 28,27 & 21,84 \\
\hline $\begin{array}{l}\text { Farelo de soja } \\
\text { Soybean meal }\end{array}$ & 0,42 & 7,08 & 13,83 & 20,42 & 27,00 \\
\hline $\begin{array}{l}\text { Calcário } \\
\text { Limestone }\end{array}$ & 0,84 & 0,83 & 0,83 & 0,83 & 0,80 \\
\hline $\begin{array}{l}\text { Fosfato bicálcico } \\
\text { Dicalcium phosphate }\end{array}$ & 0,33 & 0,33 & 0,29 & 0,21 & 0,10 \\
\hline $\begin{array}{l}\text { Sal } \\
\text { Salt }\end{array}$ & 0,08 & 0,13 & 0,13 & 0,11 & 0,10 \\
\hline $\begin{array}{l}\text { Premix }{ }^{1} \\
\text { Premix }\end{array}$ & 0,17 & 0,17 & 0,17 & 0,17 & 0,16 \\
\hline $\begin{array}{l}\mathrm{MS}(\%) \\
D M\end{array}$ & 87,8 & 89,6 & 88,7 & 88,7 & 88,7 \\
\hline $\begin{array}{l}\mathrm{EB}(\mathrm{Mcal} / \mathrm{kg}) \\
G E\end{array}$ & 4,30 & 4,22 & 4,22 & 4,21 & 4,27 \\
\hline $\begin{array}{l}\mathrm{PB}(\%)^{2} \\
C P\end{array}$ & 7,45 & 10,26 & 13,23 & 16,04 & 18,51 \\
\hline $\begin{array}{l}\mathrm{FDN}(\%)^{2} \\
N D F\end{array}$ & 55,78 & 54,98 & 56,54 & 56,78 & 56,42 \\
\hline $\begin{array}{l}\text { Cinzas }(\%)^{2} \\
\text { Ashes }\end{array}$ & 4,87 & 4,32 & 5,68 & 5,76 & 5,84 \\
\hline
\end{tabular}

imediatamente após a defecação e armazenadas em baldes de plástico. A cada período de seis horas, as fezes de cada animal foram pesadas, retirada amostra referente a $10 \%$ do peso total das fezes coletadas. As quais foram mantidas sob refrigeração. Ao término de cada dia, as quatro amostras de cada animal foram homogenizadas, e retirada uma amostra composta diária com aproximadamente $300 \mathrm{~g}$, sendo esta armazenada a $-10^{\circ} \mathrm{C}$.

As análises de matéria seca (MS), energia bruta (EB), proteína bruta (PB), fibra em detergente neutro (FDN), fibra em detergente ácido (FDA) e cinzas das amostras de alimentos, das sobras e fezes foram feitas segundo a metodologia descrita por Silva (1990). $\mathrm{O}$ teor de cromo nas amostras de fezes e sobras foi determinado por espectrofotometria de absorção atômica, segundo a metodologia descrita por Willians et al. (1962). Os teores de FDNi, FDAi, CELi, LIG e CIDA nas amostras de alimentos, de sobras e de fezes foram obtidos após incubação in vitro, segundo a metodologia descrita por Cochran et al. (1986).

Os coeficientes de digestibilidade aparente das dietas foram estimados de forma indireta com o uso de indicadores internos FDN indigestível (FDNi), FDA indigestível (FDAi), celulose indigestível (CELi), lignina (LIG) e cinzas insolúveis em detergente ácido (CIDA) e do oxido crômico como indicador externo, segundo Church (1979).

O delineamento experimental utilizado no primeiro ensaio foi o de blocos ao acaso com seis tratamentos (coleta total de fezes e indicadores) e quatro blocos (períodos). O modelo estatístico adotado foi:

$$
Y_{i j k}=\mu+T_{i}+B_{j}+D_{k}+e_{i j k}
$$

em que: $Y_{i j k}=$ corresponde à observação relativa à dieta $\mathrm{k}$, ao bloco $\mathrm{j}$, para o tratamento $\mathrm{i}, \mu=$ a média geral, $T_{i}=o$ efeito do tratamento $i$, sendo $i=1$ a 6 , $B_{j}=$ o efeito do bloco $\mathrm{j}$, sendo $\mathrm{j}=1 \mathrm{a} 4, \mathrm{Dk}=\mathrm{o}$ efeito da dieta $\mathrm{k}$, sendo $\mathrm{k}=1$ a 5 e $\mathrm{e}_{\mathrm{ijk}}=\mathrm{o}$ erro experimental associado a cada observação.

O delineamento utilizado no segundo ensaio foi 
Tabela 2 - Composição percentual dos ingredientes e percentuais de proteína bruta (PB), fibra em detergente neutro (FDN) e fibra em detergente ácido (FDA), expressos na matéria seca das dietas (ensaio 2)

Table 2 - Ingredient percentage and contents of crude protein (CP), neutral detergent fiber (NDF) and acid detergent fiber (ADF), in dietary dry matter basis (assay 2)

\begin{tabular}{|c|c|c|c|c|}
\hline \multirow[t]{2}{*}{$\begin{array}{l}\text { Ingrediente/Nutriente } \\
\text { Ingredient/Nutrient }\end{array}$} & \multicolumn{4}{|c|}{$\begin{array}{l}\text { Proporção volumoso : concentrado } \\
\text { Forage to concentrate ratio }\end{array}$} \\
\hline & $40: 60$ & $60: 40$ & $80: 20$ & 100:00 \\
\hline $\begin{array}{l}\text { Feno de capim-coastcross } \\
\text { Coastcross hay }\end{array}$ & 40 & 60 & 80 & 100 \\
\hline $\begin{array}{l}\text { Milho grão } \\
\text { Corn grain }\end{array}$ & 43,5 & 26,4 & 7,0 & 0 \\
\hline $\begin{array}{l}\text { Farelo de soja } \\
\text { Soybean meal }\end{array}$ & 14,5 & 12,0 & 11,2 & 0 \\
\hline $\begin{array}{l}\text { Suplemento mineral-vitamínico } \\
\text { Mineral-vitamin } \text { mix }^{1}\end{array}$ & 1,0 & 0,8 & 0,8 & 0 \\
\hline $\begin{array}{l}\text { Sal } \\
\text { Salt }\end{array}$ & 1,0 & 0,8 & 1,0 & 0 \\
\hline $\begin{array}{l}\operatorname{MS}(\%) \\
D M(\%)\end{array}$ & 90,1 & 89,6 & 90,4 & 91,1 \\
\hline $\begin{array}{l}\mathrm{PB}(\%) \\
C P(\%)\end{array}$ & 12,5 & 13,3 & 12,1 & 7,3 \\
\hline $\begin{array}{l}\mathrm{FDN}(\%) \\
N D F(\%)\end{array}$ & 37,1 & 50,0 & 63,0 & 75,7 \\
\hline $\begin{array}{l}\mathrm{FDA}(\%) \\
A D F(\%)\end{array}$ & 19,1 & 26,6 & 33,7 & 40,6 \\
\hline
\end{tabular}

o quadrado latino 4 x 4 , sendo quatro tratamentos (dietas com diferentes níveis de fibra), quatro animais, sendo o animal na repetição considerado como unidade experimental. O modelo estatístico adotado foi:

$$
Y_{i j k}=\mu+P_{i}+A_{j}+D_{k}+e_{i j k}
$$

em que: $Y_{i j k}=$ corresponde à observação relativa à dieta $\mathrm{k}$, no período $\mathrm{i}$, para o animal $\mathrm{j}, \mu=\mathrm{a}$ média geral, $\mathrm{P}_{\mathrm{i}}=$ o efeito do período $\mathrm{i}$, sendo $\mathrm{i}=1 \mathrm{a} 4, \mathrm{~A}_{\mathrm{j}}=\mathrm{o}$ efeito do animal $\mathrm{j}$, sendo $\mathrm{j}=1$ a $4, \mathrm{D}_{\mathrm{k}}=\mathrm{o}$ efeito da dieta $\mathrm{k}$, sendo $\mathrm{k}=1$ a 4 e $_{\mathrm{ijk}}=\mathrm{o}$ erro experimental associado a cada observação.

Os valores obtidos foram submetidos à análise de variância e os valores médios dos coeficientes de digestibilidade aparente dos nutrientes, comparados pelo teste Tukey, adotando-se o nível de 5\% de probabilidade. Utilizou-se o programa SAEG - Sistema para Análises Estatísticas e Genéticas (UFV, 1997).

\section{Resultados e Discussão}

Os valores médios dos coeficientes de digestibilidade aparente da matéria seca, energia bruta e fibra em detergente neutro, obtidos com coleta total de fezes e com os indicadores externos e internos, e as taxas de recuperação fecais dos indicadores avaliados no ensaio 1 podem ser observados na Tabela 3.

Não houve diferença entre os valores dos CDMS estimados pela fibra em detergente ácido indigestível e celulose indigestível comparados com os obtidos pelo método de coleta total de fezes. Os valores de CDMS estimados com o óxido crômico e a lignina apresentaram-se subestimados, enquanto o valor estimado com a CIDA se apresentou superestimado em relação ao método da coleta total de fezes.

A baixa recuperação fecal da lignina tem sido um fator limitante do uso em ensaios de digestão com bovinos (Kotb \& Luckey, 1972), o que também foi observado por Machado (1992) e Miraglia et al. (1999), em ensaios de digestão com eqüinos, com 58,3 e 59,0\% de recuperação fecal da lignina, respectivamente.

Estes resultados estão relacionados com o percentual de recuperação dos indicadores nas fezes, de 98,75 e 101,72\% para a fibra em detergente ácido indigestível (FDAi) e celulose indigestível (CELi), de $71,17,75,81$ e 168,65\% para o óxido crômico, a lignina e a cinzas insolúveis em detergente ácido (CIDA), respectivamente. A baixa recuperação fecal do óxido crômico em ensaios de digestão com eqüinos foi 
Tabela 3 - Médias e coeficientes de variação (CV) dos coeficientes de digestibilidade aparente da matéria seca (MS), energia bruta (EB) e fibra em detergente neutro (FDN) obtidos com coleta total de fezes e com os indicadores externos e internos e taxa de recuperação fecal dos indicadores

Table 3 - Means and coefficients of variation (CV) of the coefficients of apparent digestibility of dry matter (DM), gross energy (GE) and neutral detergent fiber (NDF) obtained with total feces collection and with the external and internal markers and the fecal marker recovery rates

\begin{tabular}{|c|c|c|c|c|}
\hline \multirow[t]{2}{*}{$\begin{array}{l}\text { Item } \\
\text { Item }\end{array}$} & \multicolumn{3}{|c|}{$\begin{array}{l}\text { Coeficiente de digestibilidade aparente (\%) } \\
\text { Coefficient of apparent digestibility }(\%)\end{array}$} & \multirow[t]{2}{*}{$\begin{array}{c}\text { Taxa de recuperação dos indicadores (\%) } \\
\text { Marker recovery rate (\%) }\end{array}$} \\
\hline & $\begin{array}{l}\text { MS } \\
D M\end{array}$ & $\begin{array}{l}\mathrm{EB} \\
G E\end{array}$ & $\begin{array}{l}\text { FDN } \\
N D F\end{array}$ & \\
\hline Coleta total de fezes & $63,45^{b}$ & $60,83^{d}$ & $50,70^{b}$ & - \\
\hline $\begin{array}{l}\text { Total feces collection } \\
\text { Óxido crômico } \\
\text { Chromic oxide }\end{array}$ & $48,39^{\mathrm{c}}$ & $79,68^{\mathrm{c}}$ & $25,85^{\mathrm{d}}$ & 71,17 \\
\hline $\begin{array}{l}\text { FDAi } \\
i A D F\end{array}$ & $62,42^{\mathrm{b}}$ & $62,42^{\mathrm{d}}$ & $62,42^{\mathrm{a}}$ & 98,75 \\
\hline $\begin{array}{l}\text { CELi } \\
i C E L\end{array}$ & $63,35^{b}$ & $85,62^{b}$ & $47,25^{b}$ & 101,72 \\
\hline $\begin{array}{l}\text { Lignina } \\
\text { Lignin }\end{array}$ & $51,88^{\mathrm{c}}$ & $81,10^{\mathrm{c}}$ & $32,54^{\mathrm{c}}$ & 75,81 \\
\hline $\begin{array}{l}\text { CIDA } \\
\text { iAAF }\end{array}$ & $77,15^{\mathrm{a}}$ & $91,00^{\mathrm{a}}$ & $67,16^{\mathrm{a}}$ & 168,65 \\
\hline CV $(\%)$ & 9,3 & 3,1 & 14,5 & \\
\hline
\end{tabular}

Médias seguidas de letras diferentes na coluna diferem $(P<0,05)$ entre si, pelo teste Tukey.

Means followed by different letters, within a column, are different $(P<.05)$ by Tukey test.

relatada por Pereira et al. (1995) e Maurício et al. (1996), de 82,7 e $80,0 \%$, respectivamente.

Segundo Cuddeford \& Hughes (1990), a excreção fecal diária do óxido crômico não é constante, o que pode levar a erros nas estimativas da digestibilidade aparente dos nutrientes.

No ensaio 1, os teores de FDAi, CELi, LIG e CIDA nas dietas podem ser observados na Tabela 4.

Os elevados percentuais de recuperação fecal da

Tabela 4 - Teores médios (\% na matéria seca) da fibra em detergente ácido indigestível (FDAi), celulose indigestível (CELi), lignina (LIG) e cinzas insolúveis em detergente ácido (CIDA) nas dietas

Table 4 - Average contents (\% dry matter) of indigestible acid detergent fiber (iADF), indigestible neutral detergent fiber (iNDF), indigestible cellulose (iCEL), lignin (LIG) and acid detergent insoluble ash $(A D I A)$ in the diets

\begin{tabular}{|c|c|c|c|c|c|}
\hline \multirow[t]{2}{*}{$\begin{array}{l}\text { Item } \\
\text { Item }\end{array}$} & \multicolumn{5}{|c|}{$\begin{array}{l}\text { Dieta } \\
\text { Diet }\end{array}$} \\
\hline & 1 & 2 & 3 & 4 & 5 \\
\hline $\begin{array}{l}\text { FDAi } \\
I A D F\end{array}$ & 9,87 & 9,83 & 9,79 & 9,88 & 9,76 \\
\hline $\begin{array}{l}\text { CELi } \\
\text { ICEL }\end{array}$ & 5,77 & 5,66 & 5,54 & 5,62 & 5,48 \\
\hline $\begin{array}{l}\text { Lignina } \\
\text { Lignin }\end{array}$ & 3,51 & 3,58 & 3,62 & 3,60 & 3,64 \\
\hline $\begin{array}{l}\text { CIDA } \\
\text { IAAD }\end{array}$ & 0,72 & 0,71 & 0,74 & 0,78 & 0,76 \\
\hline
\end{tabular}

R. Bras. Zootec., v.32, n.6, p.1681-1689, 2003 (Supl. 1)
CIDA obtidos no presente ensaio podem estar relacionados com o método de coleta fecal, diretamente do piso da baias, elevando a concentração do teor de cinzas nas amostras de fezes. Estimativas adequadas da digestibilidade de nutrientes em ensaios de digestão com eqüinos, usando-se a CIDA como indicador interno, foram observadas por Machado (1992) e Araújo et al. (2000), utilizando gaiolas de metabolismo.

Os valores médios dos coeficientes de digestibilidade aparente da MS, EB, FDN e FDA, determinados por coleta total de fezes e estimados com o uso dos indicadores internos FDNi, FDAi, CELi e LIG no ensaio 2, são apresentados na Tabela 5.

Os coeficientes de digestibilidade aparente da MS, EB, FDN e FDA obtidos com a coleta total de fezes e estimados com a CELi foram similares e diferiram dos valores estimados com a FDNi, FDAi e LIG. Pode-se inferir, portanto, que a CELi, como indicador interno fecal, foi que a melhor estimou os coeficientes de digestibilidade dos nutrientes quando comparado ao método da coleta total de fezes. A FDNi e a FDAi superestimaram os coeficientes de digestibilidade dos nutrientes, quando comparados ao método da coleta total de fezes. Resultados semelhantes foram observados por Oliveira (1998), indicando a CELi como o melhor indicador interno para se estimar a digestibilidade aparente de dietas para eqüinos. 
Tabela 5 - Valores médios dos coeficientes de digestibilidade aparente de nutrientes determinados por coleta total fecal e estimados com o uso dos indicadores internos

Table 5 - Mean values of the coefficients of apparent digestibility of nutrients determined by total feces collection and estimated with internal markers

\begin{tabular}{lcccc}
\hline Indicadores & \multicolumn{4}{c}{$\begin{array}{c}\text { Coeficiente de digestibilidade (\%) } \\
\text { Coefficient of digestibility (\%) }\end{array}$} \\
\cline { 2 - 5 } & $\mathrm{MS}$ & $\mathrm{EB}$ & $\mathrm{FDN}$ & $\mathrm{FDA}$ \\
& $D M$ & $G E$ & $N D F$ & $A D F$ \\
\hline $\begin{array}{l}\text { Coleta total de fezes } \\
\text { Total feces collection }\end{array}$ & $54,41^{\mathrm{d}}$ & $58,85^{\mathrm{c}}$ & $46,65^{\mathrm{c}}$ & $36,96^{\mathrm{c}}$ \\
FDNi & $60,45^{\mathrm{c}}$ & $64,79^{\mathrm{b}}$ & $54,89^{\mathrm{b}}$ & $46,75^{\mathrm{b}}$ \\
iNDF & $63,81^{\mathrm{b}}$ & $67,74^{\mathrm{a}}$ & $58,73^{\mathrm{ab}}$ & $51,29^{\mathrm{ab}}$ \\
FDAi & $55,06^{\mathrm{d}}$ & $60,01^{\mathrm{c}}$ & $48,18^{\mathrm{c}}$ & $38,92^{\mathrm{c}}$ \\
iADF & $67,37^{\mathrm{a}}$ & $70,92^{\mathrm{a}}$ & $62,77^{\mathrm{a}}$ & $56,02^{\mathrm{a}}$ \\
$\begin{array}{l}\text { iCEL } \\
\text { Lignina }\end{array}$ & & & & \\
Lignin & & & & \\
\hline
\end{tabular}

Médias seguidas de letras distintas, nas colunas, diferem $(\mathrm{P}<0,05)$ entre si pelo teste Tukey.

Means followed by different letters, within a column, are different $(P<.05)$ by Tukey test.

Os valores médios de recuperação fecal dos indicadores internos FDN indigestível (FDNi), FDA indigestível (FDAi), celulose indigestível (CELi) e lignina (LIG) podem ser observados na Tabela 6 .

Observou-se interação entre o método de estimativa do coeficiente de digestibilidade e as dietas na determinação do CDPB, sendo os resultados mostrados na Tabela 7.

Observou-se que a CELi foi o indicador interno que melhor estimou a CDPB em dietas com até $80 \%$ de volumoso, considerando-se o método da coleta total de fezes. Os indicadores FDNi, FDAi e LIG, superestimaram a CDPB, não se mostrando adequados como indicadores da estimativa da digestibilidade de nutrientes em dietas para eqüinos.

Os valores dos coeficientes de digestibilidade para a coleta total no ensaio 1, para a MS, EB e FDN, de 63,$45 ; 60,83$ e 50,70 , foram melhores do que no ensaio 2 de 54,41; 58,85 e 46,65, respectivamente.

Pereira et al. (1989), ao fornecerem para eqüinos dietas compostas por feno de aveia e concentrado nas proporções 100:00, 80:20, 60:40 e 40:60, observaram para os valores de coeficiente digestibilidade da MS, PB, EB FDN comportamento linear positivo, em função do aumento dos níveis de concentrado nas dietas. Os valores de CDMS e CDEB foram semelhantes aos observados no ensaio 2, mas diferentes dos valores de
CDPB, em que os autores observaram crescimento linear, em função da inclusão de concentrado nas dietas.

Darlington \& Hershberger (1968) observaram que a digestão da matéria seca, proteína bruta e energia bruta foi inversamente relacionada com a porcentagem de fibra bruta na dieta. Vander Noot \& Gilbraith (1970), alimentando equinos com diferentes volumosos, também verificaram relação inversa entre o conteúdo de fibra bruta do alimento e a digestibilidade dos nutrientes. Já Martin-Rosset \& Dulphy (1987), alimentando eqüinos ad libitum com dietas mistas de feno de gramínea e concentrado, nas proporções de 0, 30, 60 e 90\% de volumoso, não observaram efeito significativo do nível de ingestão na digestibilidade dos nutrientes nas dietas, e que a digestibilidade da forragem não foi afetada pela inclusão do concentrado.

No ensaio 2, o aumento do consumo de fibras pode ter interferido na digestibilidade da MS e da EB da dieta. Observou-se redução linear $(\mathrm{P}<0,05)$ no CDEB, com o aumento na proporção de volumoso na dieta, com valores de $71,17 \%$ para a dieta com $40 \%$ de volumoso até $48,61 \%$, para a dieta com $100 \%$ de volumoso. Comportamento semelhante foi observado por Pereira et al. (1989), quando utilizaram proporções semelhantes de volumoso. Os valores encontrados e resposta nos comportamento dos dados dos CD, podem ser explicados por argumentação de Wolter (1975), na qual o autor citou que níveis elevados de fibra na dieta podem promover aumento na motilidade intestinal, prejudicando a digestibilidade dos nutrientes no intestino delgado.

Ainda no ensaio 2, não foram observados efeitos dos níveis de volumoso nas dietas sobre os coeficientes de digestibilidade aparente da FDN e FDA, estimando-se valores médios de 46,65 e 36,96\%, respectivamente. Hintz et al. (1971) não observaram efeitos associativos entre os níveis de concentrado e volumoso nas dietas e os coeficientes de digestibilidade das frações fibrosas, entretanto, Pagan et al. (1998) observaram que os CDFDN e CDFDA em dietas mistas foram menores do que em dietas exclusivas com alimentos volumosos. A média dos valores de CDFDA observada no ensaio 2 foi de $36,96 \%$, inferior àquelas observadas por Hintz et al. (1972), de $44,42 \%$, e por Pereira et al. (1989), de 44,42\%, mas superior àquela relatada por Rezende et al. (1998).

Fombelle et al. (1999), utilizando dietas para pôneis com proporções de volumoso de 100, 70 e 50\% e cevada como alimento exclusivo no concentrado, 
Tabela 6 - Taxas médias de recuperação fecal dos indicadores internos, em função do nível de foragem na dieta

Table 6 - Mean fecal recovery rates of internal markers, in function of forage level in diets

\begin{tabular}{|c|c|c|c|c|}
\hline \multirow[t]{2}{*}{$\begin{array}{l}\text { Indicadores } \\
\text { Markers }\end{array}$} & \multicolumn{4}{|c|}{$\begin{array}{l}\text { Proporção volumoso : concentrado } \\
\text { Forage to concentrate ratio }\end{array}$} \\
\hline & $40: 60$ & $60: 40$ & $80: 20$ & 100:00 \\
\hline & \multicolumn{4}{|c|}{ Recuperação (\%) } \\
\hline & \multicolumn{4}{|c|}{ - Recovery (\%) } \\
\hline FDNi & 108,31 & 118,37 & 110,80 & 137,87 \\
\hline$i N D F$ & & & & \\
\hline FDAi & 121,58 & 122,88 & 122,66 & 153,78 \\
\hline$i A D F$ & & & & \\
\hline CELi & 141,08 & 130,30 & 138,17 & 172,51 \\
\hline ICEL & & & & \\
\hline Lignina & 98,42 & 110,13 & 95,88 & 111,29 \\
\hline Lignin & & & & \\
\hline
\end{tabular}

constataram diferenças significativas entre as dietas com 100 e 50\% volumoso, em que a adição do concentrado resultou em aumento significante da digestibilidade da matéria orgânica e redução no CDFDA e o CDFDN foi significativamente menor na dieta contendo $100 \%$ de volumoso, quando comparada às dietas com cevada.

Pagan (2001), avaliando 30 diferentes dietas para eqüinos, com vários tipos de alimentos volumosos e combinações entre eles nas dietas, observou valores médios de digestibilidade da PB em $86,1 \%$, da FDA em 40,2\% e da FDN em 45,0\%. O valor de CDPB é muito superior ao maior valor relatado no experimento 2 que foi de $69,19 \%$ na dieta com $60 \%$ de volumoso, mas os valores de CDFDA e CDFDN observados no ensaio 2 são similares aos obtidos pelo autor.

Almeida et al. (1999), alimentando eqüinos com dieta exclusiva de capim-coastcross, observaram valores médios para os coeficientes de digestibilidade aparente de $49,80 \%$ para a MS, $47,90 \%$ para a EB, $56,10 \%$ para a $\mathrm{PB}$ e $63,30 \%$ para a FDN, superiores aos valores de CDMS, de 42,54\%, de CDEB, de $48,61 \%$, de CDPB, de $44,53 \%$ e de CDFDN, de $47,40 \%$ obtidos com o feno de coastcross no ensaio 2 . Almeida (1999) observou valor médio da digestibilidade aparente total da MS, de $64,0 \%$, para dietas exclusivas de volumosos, sendo $31,8 \%$ superior aos resultados médios observados por Alvarenga (1996) e 20\% superiores aos observados por Oliveira (1998), de 43,7 e $52,0 \%$, respectivamente.

A celulose foi o melhor indicador interno na estimativa dos coeficientes de digestibilidade dos nutrientes em relação a coleta total fecal, nos dois ensaios, não apresentando diferenças significativas entre os valores dos coeficientes de digestibilidade para a MS, EB FDN e FDA, nos dois ensaios.

A FDAi como indicador interno para os coeficientes de digestibilidade da MS, EB e FDN, no primeiro ensaio, não obteve valores com diferenças significativas em relação ao método da coleta total, sendo avaliada como um bom indicador interno em ensaios com eqüinos. Já no segundo ensaio, os valores obtidos por intermédio da FDAi para os coeficientes de digestibilidade da MS, EB e FDN foram superestimados em relação aos valores obtidos pelo método da coleta total fecal.

A lignina apresentou baixa recuperação fecal no primeiro ensaio e subestimou os coeficientes de digestibilidade da MS e FDN de 51,88 e 32,54 em relação a coleta total de 63,45 e 50,70 , respectivamente. No segundo ensaio, o efeito da lignina foi contrário, uma vez que sua taxa de recuperação fecal foi alta $(103,93)$ e superestimou os coeficientes de digestibilidade da MS, EB, FDN e FDA de 67,73; 70,$92 ; 62,77$ e 56,02, em relação ao método da coleta total, de 54,$41 ; 58,85 ; 46,65$ e 36,96 , respectivamente.

Penning \& Johnson (1983), utilizando alimentos volumosos para eqüinos, observaram valores do coeficiente de digestibilidade da matéria orgânica estimados com maior precisão pelo indicador interno FDAi, quando comparado aos valores determinados pela CT, em comparação aos valores com o uso da LIG e da cinza insolúvel em ácido (CIA).

Resultados diferentes foram relatados por Maurício et al. (1996), que avaliando dietas mistas com feno Coast-cross e concentrado para eqüinos, utilizaram a lignina na estimativa dos coeficientes de digestibilidade e, observaram que os valores de CDFDN e CDFDA estimados pela LIG foram inferiores aos estimados pela coleta total de fezes. De acordo com Fahey \& Jung (1983), a lignina pode ser utilizada como indicador, apenas quando houver evidências de não existir alta recuperação fecal.

Miraglia et al. (1999), avaliando dietas mistas para eqüinos com diferentes tipos de concentrados, estimaram os coeficientes de digestibilidade dos nutrientes através da coleta total de fezes e com os indicadores internos LIG e CIA. Os valores dos coeficientes de digestibilidade estimados pela CIA foram muito próximos aos próximos aos estimados pela coleta total de fezes, de 58,28 e $61,22 \%$ para o CDMS e de 61,67 e $61,13 \%$ para o CDEB, estimados com a CIA e o método da coleta total de fezes, respectivamente, sendo os dois métodos indicados em 
Tabela 7 - Coeficientes de digestibilidade aparente da proteína bruta (CDPB) estimados pelos indicadores internos e pela coleta total de fezes (CT), em função do nível de volumoso nas dietas

Table 7 - Coefficients of apparent digestibility of crude protein $(C P D C)$, estimated by internal markers and total feces collection, in function of the dietary forage levels

\begin{tabular}{|c|c|c|c|c|}
\hline \multirow[t]{2}{*}{$\begin{array}{l}\text { Indicadores } \\
\text { Markers }\end{array}$} & \multicolumn{4}{|c|}{$\begin{array}{c}\text { Proporção volumoso : concentrado } \\
\text { Forage to concentrate ratio }\end{array}$} \\
\hline & $40: 60$ & $60: 40$ & $80: 20$ & 100:00 \\
\hline & \multicolumn{4}{|c|}{$-\operatorname{CDPB}(\%)-$} \\
\hline $\begin{array}{l}\text { Coleta total de fezes } \\
\text { Total fece collectior }\end{array}$ & $64,00^{\mathrm{c}}$ & $69,19^{d}$ & $62,31^{b}$ & $44,52^{\mathrm{c}}$ \\
\hline $\begin{array}{l}\text { FDNi } \\
i N D F\end{array}$ & $79,04^{\mathrm{ab}}$ & $77,57^{\mathrm{bc}}$ & $70,88^{a}$ & $48,70^{\mathrm{bc}}$ \\
\hline $\begin{array}{l}\text { FDAi } \\
i A D F\end{array}$ & $81,24^{\mathrm{ab}}$ & $79,78^{a b}$ & $72,08^{\mathrm{a}}$ & $54,24^{\mathrm{ab}}$ \\
\hline $\begin{array}{l}\text { CELi } \\
i C E L\end{array}$ & $73,37^{\mathrm{b}}$ & $74,17^{\mathrm{c}}$ & $68,27^{\mathrm{ab}}$ & $43,25^{\mathrm{c}}$ \\
\hline $\begin{array}{l}\text { Lignina } \\
\text { Lignin }\end{array}$ & $83,30^{\mathrm{a}}$ & $81,72^{\mathrm{a}}$ & $73,77^{\mathrm{a}}$ & $60,32^{\mathrm{a}}$ \\
\hline
\end{tabular}

Médias seguidas de letras distintas, nas colunas, diferem $(P<0,05)$ entre si pelo teste Tukey.

Means followed by different letters, within a column, are different $(P<.05)$ by Tukey test.

ensaios de digestão para eqüinos. Já os valores dos coeficientes de digestibilidade estimados pela LIG como indicador interno, foram muito inferiores aos estimados pela coleta total de fezes, subestimando as taxas de digestibilidade com valores de $31,35 \%$ para o CDMS e de $31,08 \%$ para o CDEB. Tal fato também foi observado por Araujo et al. (2000), avaliando dietas com proporção concentrado e volumoso de 40:60 e utilizando a lignina como indicador interno.

\section{Conclusões}

A FDNi e FDAi superestimaram os valores dos coeficientes de digestibilidade da fração fibrosa das dietas com diferentes proporções de volumoso.

Nos dois ensaios, com as diferentes relações de concentrado e volumoso, a CELi mostrou-se como o indicador interno mais adequado na estimativa da digestibilidade aparente dos nutrientes em dietas para eqüinos.

A lignina apresentou baixa recuperação fecal e mostrou-se inadequada para estimar a digestibilidade aparente em dietas para eqüinos.

ACIDA e oóxido crômico, em função da metodologia de coleta fecal, também se mostraram inadequados para as estimativas de digestibilidade em eqüinos.

\section{Agradecimento}

À Fundação de Amparo a Pesquisa do Estado de Minas Gerais e à Fundação Carlos Chagas de Aparo a Pesquisa do Estado do Rio de Janeiro, pelo financiamento dos projetos de pesquisa.

\section{Literatura Citada}

ALMEIDA, M.I.V.; FERREIRA, W.M.; ALMEIDA, F.Q. et al. Valor nutritivo do capim-elefante (Penninsetum purpureun, Schum), do feno de alfafa (Medicago sativa, L.) e do feno de capim coast-cross (Cynodon dactylon (L.) Pers.) para eqüinos.

Revista Brasileira de Zootecnia, v.28, n.4, p.743-752, 1999.

ALVARENGA, R.C. Fluxo de matéria seca ileal, metodologias de coleta de digesta e digestibilidade aparente total e parcial em eqüinos. Viçosa, $M G$ : Universidade Federal de Viçosa, 59p. 1996. Dissertação (Mestrado em Zootecnia) Universidade Federal de Viçosa, 1996.

ARAÚJO, K.V.; LIMA, J.A.F.; FIALHO, E.T. et al. Comparação dos indicadores internos com o método de coleta total para determinar a digestibilidade dos nutrientes de dietas mistas em eqüinos. Ciência Agrotécnica, v.24, n.4, p.1041-1048, 2000.

CHURCH, D.C. The ruminant animal - digestive physiology and nutrition. 2.ed. Englewood Cliffs: Prentice Hall, 1979. $564 \mathrm{p}$.

COCHRAN, R.C.; ADAMS, D.C.; WALLACE, J.D. et al. Predicting digestibility of different diets with internal markers: evaluation of four potential markers. Journal of Animal Science, v.63, n.5, p.1476-1483, 1986.

CUDDEFORD, D.; HUGHES, D. A comparison between chromium-mordanted hay and acid-insoluble ashe to determine apparent digestibility of a chaffed, molassed hay/straw mixture. Equine Veterinary Journal, v.22, p.122-125, 1990.

DARLINGTON, J.M.; HERSHBERGER, T.V. Effect of forage maturity on digestibility, intake and nutritive value of alfafa, timothy and orchardgrass by equine. Journal of Animal Science, v.27, n.6, p.1572-1576, 1968.

FAHEY, G.C.; JUNG H.G. Lignin as a marker in digestion studies: a review. Journal of Animal Science, v.57, n.1, p.220-225, 1983.

FOMBELLE, A.; JACOTOT, E.; DROGOUL, C. et al. Effect of the hay: grain ratio on digestive physiology and microbial ecosystem in ponies. In: EQUINE NUTRITION AND PHYSIOLOGY SYMPOSIUM, 16., 1999, North Caroline. Proceedings ... North Carolina: ENPS, 1999. p.151.

HINTZ, H.F.; SCHRYVER, H.F. Nitrogen utilization in ponies. Journal of Animal Science, v.34, n.4, p.592-595, 1972.

HINTZ, H.F.; HOGUE, D.E.; WALKER, E.F. et al. Apparent digestion in various segments of the digestive tract of ponies fed diets with varying roughage - grain rations. Journal of Animal Science, v.32, n.2, p.245-248, 1971.

KOTB, A.K.; LUCKEY, T.D. Markers in nutrition. Nutrition Abstract Review, v.42, p.813-845, 1972.

MACHADO, H.M. Efeito de diferentes combinações de capim-elefante (Pennisetum purpureum Schum): canade-açúcar (Saccharum officinarum L.) sobre a digestibilidade, em eqüinos, utilizando diferentes metodologias de determinação. Viçosa, MG: Universidade 
Federal de Viçosa, 1992. 71p. Dissertação (Mestrado em Zootecnia) - Universidade Federal de Viçosa, 1992.

MARTIN-ROSSET, W.; DULPHY, J.P. Digestibility interactions between forages and concentrates in horses: influence of feeding level - comparison with sheep. Livestock Production Science, v.17, p.263-276, 1987.

MAURICIO, R.M.; GONÇALVES,L.C.; RESENDE, AC. et al. Determinação da digestibilidade aparente em equídeos através do óxido crômico, da lignina e da coleta total das fezes. Arquivo Brasileiro Medicina Veterinária e Zootecnia, v.48, n.6, p.703-711, 1996.

MAYNARD, L.A.; LOOSLI, J.K.; HINTZ, H.F. et al. Animal nutrition. 7.ed. New York: McGraw-Hill, 1979. p.44-46.

MIRAGLIA, N.; BERGERO, D.; BASSANO, B. et al. Studies of apparent digestibility in horses and the use of internal markers. Livestock Production Science, v.60, p.21-25, 1999.

NATIONAL RESEARCH COUNCIL - NRC. Nutrients requeriments of horses. 5.ed. Washington, D.C.: 1989. 100p.

OLIVEIRA, A.A.M.A.; QUEIROZ, A.C.; VALADARES FILHO, S.C. et al. Digestão total e pré-cecal dos nutrientes em potros fistulados no íleo. Revista Brasileira de Zootecnia, v.27, n.2, p.331-337, 1998.

PAGAN, J.D. Forages for horses: more than just filler. In: PAGAN, J.D. (Ed.) Equine nutrition I. Versailles: Kentucky Equine Research, 2001. p.13-28.

PAGAN, J.D.; HARRIS, P.A.; BREWSTER-BARNES, T. et al. Exercise affects digestibility and rate of passage of all-forrage and mixed diets in thoroughbreds horses. Journal Nutrition, v.128, p.2704S-2707S, 1998.

PENNING, P.D.; JOHNSON, R.H. The use of internal markers to estimate herbage digestibility and intake. 1- Potenttially indigestible cellulose and acid insoluble ash. Journal of Agriculture Science, v.100, p.127-131, 1983.

PEREIRA, J.C.; CARMO, M.B.; MOTTA, W.A.F. et al. Feno de aveia (Avena bisantyna) associado ao concentrado em diferentes proporções na alimentação de equinos. Revista da Sociedade Brasileira de Zootecnia, v.18, n.5, p.359-366, 1989.
PEREIRA, J.C.; QUEIROZ, A.C.; CARMO, M.B. Avaliação de métodos para determinação da digestibilidade aparente em eqüinos. Revista da Sociedade Brasileira de Zootecnia, v.24, n.3, p.382- 390, 1995.

RESENDE, A.S.C.; GONÇALVES, L.C.; CARVALHO, M.A.G. et al. Digestibilidade aparente em eqüinos submetidos a três condutas de arraçoamento. II. Frações fibrosas. Arquivo Brasileiro Medicina Veterinária e Zootecnia, v.50, n.4, p.429-434, 1998.

SILVA, D.J. Análise de alimentos: métodos químicos e biológicos. 2.ed. Viçosa, MG: Universidade Federal de Viçosa, 1990. 166p.

SMOLDERS, E.A.A.; STEG, A.; HINDLE, V.A. Organic matter digestibility in horses and its prediciton. Netherlands Journal of Agriculture Science, v.38, p.435-447, 1990.

UNIVERSIDADE FEDERAL DE VIÇOSA - UFV. SAEG Sistema de análises estatísticas e genéticas. Viçosa: Universidade Federal de Viçosa, 1997. Manual do usuário, 150p. (versão 7.0).

Van SOEST, P.J. Nutritional ecology of the ruminant. 2.ed. Ithaca: Cornell University Press, 1994. 476p.

VANDER NOOT, G.W.; GILBRAITH, E.B. Comparative digestibility of components of forages by geldings and steers. Journal of Animal Science, v.31, p.351-355, 1970.

WILLIANS, C.H.; DAVID, D.J.; IISMAA, O. The determination of chromic oxide in feces samples by atomic spectrophotometry. Journal of Agriculture Science, v.59, p 381-385, 1962.

WOLTER, R. Alimentacion del caballo. 2.ed. Zaragoza: Acribia, 1975. $172 \mathrm{p}$. 